\title{
A study report on phylogenetic analysis of Classical swine fever virus isolated in different parts of the World
}

\author{
Sandip Chakraborty, B. M. Veeregowda \\ Department of Veterinary Microbiology, \\ Bangalore Veterinary College, KVAFS University, Karnataka, India \\ Corresponding author: Sandip Chakraborty, email: sandipc_85@yahoo.com,dinglychandru@yahoo.com \\ Received: 11-11-2011, Accepted: 16-12-2011, Published Online: 17-04-2012 \\ doi: $10.5455 /$ vetworld.2012.437-442
}

\begin{abstract}
Classical Swine Fever Virus (CSFV) is the cause of an economically important and contagious disease in all age groups of pigs. Advances in molecular methods have facilitated genetic typing of this virus which is useful for classification, to trace patterns of virus spread and exposing the weaknesses in control strategies. Moreover, the genetic comparison of the isolates obtained from a series of outbreaks with known linkages can be used to validate and to interpret the genetic typing to determine the rate of virus mutation in the field. The CSF viruses are grouped into three groups under which there are ten subgroups. This review highlights the works on phylogenetic analysis carried out by different workers from time to time in different parts of the world including India to have better understanding of the diversified genogrouping of this virus.

Key words: Analysis, Classical swine fever, Phylogenetic, Report, World
\end{abstract}

\section{To cite this article:}

Chakraborty S, Veeregowda BM (2012) A study report on phylogenetic analysis of Classical swine fever virus isolated in different parts of the World, Vet World, 5(7):437-442, doi: 10.5455/vetworld.2012.437-442

\section{I ntroduction}

Classical swine fever is a contagious viral disease of pigs with acute, chronic or persistent infections [1]. It is caused by a member of the genus Pestivirus of the family Flaviviridae. It is a globally significant disease of pig. The causative agent, classical swine fever virus (CSFV) is an enveloped virion with an icosahedral nucleocapsid with glycosylated membrane proteins. The genome of CSFV consists of a positive RNA molecule of about $12.3 \mathrm{~Kb}$, which encodes a single polyprotein that contains both structural glycoproteins and non-structural proteins $[2,3]$. The polyprotein is processed into a mature protein by viral and host cell proteases [4]. The envelop of pestiviruses contains three glycoproteins viz., E1, E2 and $\mathrm{E}^{\text {rns }}$ (a ribonuclease). The ORF is flanked by a $5^{\prime}$ and $3^{\prime}$ NTR. The large ORF encodes a single polyprotein which is co and post translationally cleaved into the proteins $\mathrm{N}$ Terminal protease $\left(\mathrm{N}^{\mathrm{pro}}\right)$, Capsid protein $\mathrm{C}$, three envelop glycoproteins viz., $\mathrm{E}^{\mathrm{rns}}$ (a ribonuclease), E1, E2, p7 and the non-structural proteins NS2, NS3, NS4A, NS4B, NS5A and NS5B. The NTR at the $5^{\prime}$ end harbours an Internal Ribosomal Entry Site (IRES).

Therefore, the RNA can directly be translated upon uncoating without the need of a cap structure. E2 is the immunogenic gene and induces high virus neutralizing titers of serum antibodies.

The possible discrimination between isolates depends on the length and variability of the target region of the genome that is used for comparisons. Exchange of data from previous studies has been greatly hampered as different genome targets for sequence determination, different phylogenetic methods for sequence analysis and different nomenclature for demonstrated genetic clusters were used.

\section{Global scenario as a whole}

Three defined fragments of the genome viz., 5' NTR, E2 and NS5B were selected by Greiser - Wilke et al. [5] and a standardized protocol for the calculation of phylogenetic trees including the nomenclature for the genetic types were established. The isolates analyzed, showed that they could be assigned into one of three main genetic groups (1, 2 and 3). Further analysis of E2 fragment of group 1 lead to three distinct subgroups. The genetic analysis of E2 fragment is important from the CSFV marker vaccine development point of view which induces protective immunity [6,7,8,9,10,11] Most historic isolates from 
Europe and America and some Asian isolates were found in group 1 and its subgroups. Most recent isolates from different regions in Europe and several from Asia were in group 2 and they were again sub grouped into 2.1,2.2 and 2.3 respectively. The earliest appearance of Group 2 viruses was in Germany in 1982. Subsequently, these viruses have been found in many different countries, up to the present time, including Italy, Sardinia, France, Belgium, UK, Austria, Switzerland, Hungary, The Czech Republic, Poland and The Slovak Republic [12,13]. Finally, viruses from Asia fell into one of the sub-groups in group 3 . The group 3 viruses had been reported mainly from Korea, Japan, Taiwan, Thailand and U.K [14,15].

\section{Scenario in different countries}

Analysis of the nucleotide sequence data generated from 5' NTR, E2 and NS5B genes of Classical Swine Fever Virus (CSFV) by Lowings et al. [16] were able to divide $115 \mathrm{CSFV}$ isolates into two major groups viz., group 1 and 2 . Most of the viruses in group 1 were of US or UK origin and included the reference strains Alfort/187 from France and Brescia from Italy. Group 2 included the viruses isolated from the Asian countries like Malayasia and Japan.

The Central European isolates of CSFV were characterized by Stadejek et al. [17] and they evaluated the applicability of molecular analysis in the epizootiology of CSFV infections. Thirty four viruses derived from Central European pigs or wild boars were examined in their study. The discriminatory ability of the technique was improved by the analysis of a composite data set consisting of all the sequence data from all the viruses. Using this approach they were not only able to distinguish between all the viruses but also were able to group them in a manner that precisely matched their geographical origins which helped in establishing the fact that the virus is genetically heterogenous in Central Europe. Phylogenetic analysis of 15 representative CSFV isolates from Cuba targeting the E2 sequences were conducted by De Arce et al. [18] and their finding showed that the viruses of Cuba clustered in subgroup 1.2. Moreover, it had been observed that the viruses isolated from 1996 in eastern Cuba defined a related, but independent group.

The level of sequence variation observed in this group didn't exclude an independent origin for the eastern isolates. Lowings et al. [19] analyzed a variable region of the gene encoding the major glycoprotein E2 of Classical Swine Fever Virus (CSFV) from 12 Sardinian isolates which had been obtained from three geographically distinct regions of the Island. Phylogenetic analysis of these viruses indicated that the Sardinian viruses were all members of the common European sub group 2.3. Bartak and Greiser - Wilke [12] sequenced fragments of 5' NTR and E2 glycoprotein gene of fourteen Czech Republican isolates and found that the isolates fall under subgroups 2.2 and 2.3. They deduced that these isolates were having more close relation with those of Australia sequenced between the years 1992 and 1994. The isolates in subgroup 2.3 formed a very homogeneous group, although they originated from different regions of the country. Epizootiological links became evident when the epidemiological data were compared. A big epidemic of classical swine fever in Germany in the 1990's were reported by Fritzemeier $e t$ al. [20]. They analyzed about 30 isolates from the outbreak by comparison of the nucleotide sequence data generated from fragments of both the E2 glycoprotein gene and 5' NTR gene. By combining epidemiological data with genetic typing, they found that the outbreak was related and caused by viruses belonging to the genetic subgroup 2.1. Several outbreaks of CSF were recorded during the period of 1997-2001 in Croatia. Jemersić et al. [21] considered nine CSFV isolated during this period and sequenced the viruses between 150 and 190 nucleotide fragments of $5^{\prime}$ NTR and E2 glycoprotein genes respectively. Their study revealed that these isolates fall under subgroups 2.1 and 2.3. Pan et al. [22] found in their study that most of the CSFV isolated in Taiwan between 1989 and 2003 fall under subgroup 2.1 and 2.2 and considered them as strains introduced in Taiwan from other places whereas a few isolates (forty three out of hundred and fifty eight) fall under subgroup 3.4 and were considered as endemic strains. Pereda et al. [23] performed genotyping of isolates from outbreaks in domestic pigs in several countries of South and Central America.

For this purpose, they selected a 190 base pair fragment of the E2 envelope glycoprotein gene. For comparison, they included European strains and isolates, and historical isolates from the United States (US) apart from their isolates. They found that all the isolates included in their analysis belonged to group 1 and were further resolved into three subgroups in contrast to the situation in most parts of Europe, where group 2 isolates predominate. The Cuban isolates and the isolates from Honduras and Guatemala fall under subgroup 1.2 and 1.3 respectively. The remaining isolates from Argentina, Brazil, Colombia and Mexico generated four poorly resolved clusters in subgroup 
1.1. This allowed in the speculation that at least in American continent, CSFV might have appeared independently in several regions and spreading might have been a secondary effect. The partial E2 gene sequence for $10 \mathrm{CSF}$ viruses isolated at different locations of the Cuban island by Heidy et al. [24] were used for phylogenetic analyses including sequences from viruses of the 1993 - 1997 epizootic, previously determined, as well as those from representatives of the different CSFV genotypes. The phylogenetic tree obtained indicated that viruses circulating at present in Cuba belong to the subgroup 1.2. Sabogal et al. [25] characterized the viruses isolated from Colombia and found them to fall under subgroup 1.1. The results indicated that the outbreaks from the year 2002 were caused by a strain related to the virus CSF/Santander, isolated in 1980, suggesting that the current CSF outbreaks are the consequence of a single strain that continues to circulate in the field till date in Colombia.

Allepuz et al. [26] reported on the descriptive epidemiology of the outbreak of CSF in Catalonia, Spain. Twenty two of the infected herds were detected on the basis of clinical suspicion on the part of the farmer or farm veterinarian, and the other 17 were detected by surveillance methods. The viruses isolated in the two waves of the outbreak were 100 per cent homologous and belonged to subgroup 2.3. The origin of the outbreak remained unknown. Cha et al. [27] genetically characterized $24 \mathrm{CSFV}$ isolates which were obtained from CSF outbreaks during 1988 and 2003 in the Republic of Korea and compared with CSF viruses reported by other countries. Phylogenetic analyses classified Korean field isolates between 1988 and 1999 into subgroups 3.2, forming an independent clade distinct from CSF viruses identified in other countries. In contrast, the viruses isolated during 2002-2003 CSF epidemics were classified into subgroup 2.1. The 2.1 viruses showed a close genetic relationship (92.1-100\%) with CSF viruses reported from China and Taiwan in 1998-2001.

Sang et al. [28] reported the phylogenetic characterization of CSF viruses isolated in Korea between 1988 and 2003. Twenty four isolates of CSFV which were obtained from CSF outbreaks during 1988 and 2003 in the Republic of Korea were genetically characterized for partial E2 gene (190 nucleotides) and compared with CSF viruses reported by other countries. Phylogenetic analysis placed the Korean field isolates of 1988 - 1999 into subgroup 3.2, forming an independent clade distinct from CSF viruses identified in their countries. In contrast, the viruses isolated during 2002-2003 CSF epidemics were classified into a different subgroup. Giangaspero and Harasawa [29] analyzed 43 strains of CSFV from outbreaks in pigs in Europe, Asia and America, two strains from commercial CSFV modified live vaccines (originally isolated by Grebennikova et al., [30]) and a strain isolated from a diseased lamb from Spain (originally isolated by Hurtado et al., [31]) in the 5' terminal region of the genome using the Palindromic Nucleotide Substitution (PNS) method. Nucleotide sequences were aligned using the method proposed by Higgins et al. [32]. Phylogenetic trees based on the 5' NTR was constructed using the unweighed pair-group method with arithmetic averages (UPGMA) described by Sneath and Sokal [33]. Nucleotide sequence secondary structures were predicted according to the algorithm of Zuker and Stiegler [34]. The minimum free energy was calculated using the method of Freier et al. [35]. Phylogenetic tree placed the isolates in group 1 . They also found that $5^{\prime}$ NTR acts as an IRES (Internal Ribosomal Entry Site) and is responsible for the genetic stability of the virion. The application of the PNS method was found to be an appropriate approach for differential diagnosis to solve crossinfections. Classical Swine fever is endemic in Peru. Little was known about the genetic subgroup of CSFV in Peru until Araínga et al. [36] phylogenetically characterized the viruses and found them to fall under subgroup 1.1. In Vietnam, Tung et al. [37] conducted study on $44 \mathrm{CSFV}$ isolates from the country along with 271 reference viruses and found that all these viruses fall under subgroup 2.1 .

\section{I ndian scenario}

Phylogenetic characterization of virulent (CSFV/ MP) and lapinised vaccine (CSFV/LAP) strains of CSFV at I.V.R.I, Izzatnagar placed both the strains into genogroup 1.1 [38]. Especially the molecular characterization of CSFV/LAP strain was a landmark as it was shown earlier that this strain of CSFV offered a longer immunity in vaccinated animals lasting for years upto lifelong and conferred wide range of immunity against different strains and genotypes $[39,40,41]$.

Barman et al. [42] found in their analysis that one of the isolate from Mizoram is closely related to the Chinese strain Shimen- HVRI rather than other Indian isolates. They assumed that as the state of Mizoram is geographically nearer to China and Myanmar, the virus might have spread during migration of animals from these neighbouring countries. 5?-NTRbased phylogenetic analysis was conducted by Desai et al. [43]. Sequence analysis and subsequent genetic 
classification of nine CSFV field isolates from India were done in their study. It was found that three isolates belonged to genotype 2.1 and were closely related to European CSFV strains whereas the remaining six isolates belonged to genotype 1 that contained old and new strains.

This study showed the prevalence of both genotypes 1 and 2.1 in north-eastern part of India and highlighted about the urgent need for the intense molecular epidemiological investigations of CSFV isolates and development of comprehensive nationwide control program for CSF to sustain the livelihood of farmers and growth of piggery industry in India. Sarma et al. [44] considered 16 CSFV isolated from different districts of Assam and typed them in 150 nucleotide fragment of $5^{\prime}$ NTR region. The genetic typing was confirmed by further analysis of 190 and 409 nucleotide fragments of the E2 and NS5B genes respectively. Their findings clearly showed that these viruses from Assam fall under subgroup 1.1 which suggested the prevalence of this particular subgroup of viruses in the state of Assam. Genetical analysis of twenty-three CSFV isolates recovered from field outbreaks by Patil et al. [45] from different parts of the country in the NS5B region showed the continued dominance of subgroup 1.1 viruses in the country. Sixteen out of these twentythree viruses were earlier analyzed targeting the $5^{\prime}$ NTR region. Chakraborty et al. [46] characterized three CSFV isolated from suburban places of Bangalore, India using molecular techniques targeting the $5^{\prime}$ NTR gene and subsequently grouped the viruses into subgroup 2.2 of group 2. Reports from Taiwan [47] Columbia [25] and Germany [48] were also suggestive of the predominant involvement of group 2 and 3 viruses in CSF outbreaks worldwide at present.

\section{Conclusion}

It is important to harmonise genetic typing methods so that the sequence data obtained in different laboratories are comparable. Providing a large collection of sequences from one or more specific target regions increases the likelihood of such regions being used in future studies also. The work of Hofmann et al. [19] and Lowings et al. [26] had already generated much data for the $5^{\prime}$ NTR, E2 and NS5B regions. Studies on phylogeny of current isolates of CSFV are a useful means to reveal the origin and diversity of CSFV. More importantly, phylogenetic studies prove to be a useful approach to aid control and eradication programme of CSF.

\section{References}

1. Moennig V. (2000). Introduction to classical swine fever: virus, disease and control policy. Vet. Microbiol., 73:93-102.

2. Meyers G., Rümenapf T., Thiel H.J. (1989). Molecular cloning and nucleotide sequence of the genome of hog cholera virus. Virol., 171:555-567.

3. Stark R., Rümenapf T., Meyers G., Thiel H.J. (1990). Genomic localization of hog cholera virus glycoproteins. Virol., 174: 286-289.

4. Knoetig S.M., Summerfield, A., Spagnuolo - Weaver M., Mc Cullough K C. (1999). Immunopathogenesis of classical swine fever: role of monocytic cells. Immunol., 97: 3-366.

5. Greiser-Wilke I., Fritzemeier J., Koenen F., Vanderhallen H., Rutili D., De Mia G.M., Romero L., Rosell R., Sanchez - Vizcaino J.M., San Gabriel A. (2000). Molecular epidemiology of a large classical swine fever epidemic in the European Union in 19971998. Vet. Microbiol., 77: 17-27.

6. Hulst M.M., Westra D.F., Wensvoort G., Moormann R.J. (1993). Glycoprotein E1 of hog cholera virus expressed in insect cells protects swine from hog cholera. J. Virol., 67(9): 5435-5442.

7. Konig M., Lengsfeld T., Pauly T., Stark R., Thiel H.J. (1995). Classical swine fever virus- Independent induction of protective immunity by 2 structural glycoproteins. J. Virol., 69: 6479-6486.

8. Peeters B., BienkowskaSzewczyk K., Hulst M., Gielkens A., Kimman T. (1997). Biologically safe, non-transmissible pseudorabies virus vector vaccine protects pigs against both Aujeszky's disease and classical swine fever. J. Gen. Virol., 78: 3311-3315.

9. Rumenapf T., Stark R., Meyers G., Thiel H.J. (1991). Structural Proteins of Hog Cholera Virus Expressed by Vaccinia Virus - further characterization and induction of protective immunity. J. Virol., 65: 589597.

10. Van Rijn P.A., Bossers A., Wensfort G. and Moormann R.J. (1996). Classical swine fewer virus (CSFV) envelope glycoprotein E2 containing one structural antigenic unit protects pigs from lethal CSFV challenge. J. Gen. Virol. 77(11): 2737-2745.

11. Van Zijl M., Wensvoort G., de Kluyver E., Hulst M., Van der Gulden H., Gielkens A., Berns A., Moormann R. (1991). Live attenuated pseudorabies virus expressing envelope glycoprotein E1 of hog cholera virus protects swine against both pseudorabies and hog cholera. J. Virol. 65(5): 2761-2765.

12. Bartak P., Greiser-Wilke I. (2000). Genetic typing of classical swine fever virus isolates from the territory of the Czech Republic. Vet. Microbiol.,77: 59-70.

13. Hofmann M.A., Brechtbuhl K., Stauber N. (1994). Rapid characterization of new pestivirus strains by direct sequencing of PCR-amplified cDNA from the 5'-noncoding region. Arch. Virol., 139: 217-229.

14. Paton D.J, Mc Goldrick A., Greiser - Wilke I., 
Parchariyanon S., Song J Y., Liou P.P., Stadejek T., Lowings J.P., Björklund H., Belak S. (2000). Genetic typing of classical swine fever virus. Vet. Microbiol., 73: 137-157.

15. Sakoda Y., Ozawa S., Damrongwatanopokin S., Sato M., Ishikawa K., Fukusho A. (1999). Genetic heterogenicity of porcine and ruminant viruses mainly isolated in Japan. Vet. Microbiol., 65: 75-86.

16. Lowings P., Ibata G., Needham J., Paton D. (1996). Classical swine fever virus diversity and evolution. $J$. Gen. Virol.,77: 1311-1321.

17. Stadejek T., Vilcek S., Lowings J.P., Ballagi-Pordany A., Paton D.J., Belak S. (1997). Genetic heterogeneity of classical swine fever virus in central Europe. Virus Res., 52: 195-204.

18. De Arce H.D., Nunez J.I., Lliliane G., Barreras M., Frees M.T., Sobrino F. (1999). Molecular epidemiology of classical swine fever in Cuba. Virus Res., 64: 61-67.

19. Lowings P., Ibata G., De Mia G.M., Rutili D., Paton D. (1999). Classical swine fever in Sardinia: epidemiology of recent outbreaks. Epidemiol. Infect., 122: 553-559.

20. Fritzemeier J., Teuffert J., Greiser - Wilke I., Staubach C., Schluter H., Moennig V. (2000). Epidemiology of classical swine fever in Germany in the 1990s. Vet. Microbiol., 77: 29-41.

21. Jemersić L., Greiser - Wilke I., Barlic-Maganza D., Lojkic M., Madic J., Terzic S., Grom J. (2003). Genetic typing of recent classical swine fever virus isolates from Croatia. Vet. Microbiol., 96: 25-33.

22. Pan C.H, Jong M.H, Huang T.S, Liu H.F, Lin S.Y, Lai S.S. (2004). Phylogenetic analysis of classical swine fever virus in Taiwan. Experimental Report AHRI, 40: 90-110.

23. Pereda A.J., Greiser-Wilke I., Schmitt B., Rincon M.A., Mogollon J.D., Sabogal Z.Y., Lora A.M., Sanguinetti H., Piccone M.E. (2005). Phylogenetic analysis of classical swine fever virus (CSFV) field isolates from outbreaks in South and Central America. Virus Res., 110 (1-2): 111-118.

24. Heidy D., Lliliane G., Martiza B., Dany N., Francisco S., Maria T.F., Jose I.N. (2005). Origin and evolution of viruses causing classical swine fever in Cuba. Sci. Direct., 112: 123-131.

25. Sabogal Z.Y., Mogollon J.D., Rincon M.A., Clavijo A. (2006). Phylogenetic analysis of recent isolates of classical swine fever virus from Colombia. Virus Res., 115: 99-103.

26. Allepuz A., Casal J., Jove R., Helga I., Porcar J., Domingo M. (2007). Descriptive epidemiology of the outbreak of classical swine fever in Catalonia (Spain), 2001/2002. Vet. Rec., 160: 398-403.

27. Cha S.H., Eun J.C., Choi E.J., Park J.H., Yoon S.R., Kwon J.H., Yoon K. J., Song J.Y. (2007). Phylogenetic characterization of classical swine fever viruses isolated in Korea between 1988 and 2003. Virus Res., 126: 256-261.
28. Sang H.C., Eun J.C., Jong H.P., So R.Y., Jun H. K., Kyoung J.Y., Jae Y.S. (2007). Phylogenetic characterization of classical swine fever viruses isolated in Korea between 1988 and 2003. Virus Res., 126: 256-261.

29. Gianggaspero M., Harasawa R. (2008). Genetic variation of classical swine fever virus based on palindromic nucleotide substitutions, a genetic marker in the 5' untranslated region of RNA. Veterinaria Italiana, 44(2): 305-318.

30. Grebennikova T.V., Zaberezhnyi A.D., Sergeev V.A., Biketov S.F., Aliper T.I., Nepoklonov E.A. (1999). Genetic characteristics of the K.C vaccine strain of hog cholera virus: comparative analysis of the primary sequence of surface glycoprotein E (rns), E1 and E2 genes. Mol. Gen. Mikrobiol. Virusol., 2: 34-40.

31. Hurtado A., Garcia - Perez A.L., Aduriz G., Juste R.A. (2003). Genetic diversity of ruminant pestiviruses from Spain. Virus Res., 92: 67-73.

32. Higgins D.G, Bleasby A.J., Fouchs R. (1992). Clastal $\mathrm{V}$ : improved software for multiple sequence alignment. Comp. Appl. Biol. Sci., 8: 189-191.

33. Sneath P.H.A., Sokal R.R. (1973). Numerical taxonomy: the principles and practice of numerical classification. W.H. Freeman, San Francisco, 573 pp.

34. Zuker M., Stiegler P. (1981). Optimal computer folding of large RNA sequences using thermodynamics and auxillary. Nucleic Acids Res. 9: 133148.

35. Freier S.M., Kierzek R., Jaege J.A., Sugimoto N., Caruthers M.H., Nielson T., Turner D.H. (1986). Improved free-energy parameters for predictions of RNA duplex stability. Proc. Natl. Acad. Sci., USA 83: 9373-9377.

36. Arainga M., Hisanaga T., Hills K., Handel K., Rivera H., Pasick J. (2010). Phylogenetic analysis of classical swine fever virus isolates from Peru. Transboundary and emerging diseases, 57: 262-270.

37. Tung N., Dang N.H., Hoa D.T., Vui D.T., Tho N.D., Inui K. (2011). Genetic Analysis of Classical Swine Fever Viruses from Vietnam in 2010. Proceedings of the $5^{\text {th }}$ Asian Pig Veterinary Society Congress.

38. Singh V.K, Sai Kumar G., Bandyopadhyay S.K., Paliwal O.P. (2006). Phylogenetic analysis of classical swine fever virus by cloning and sequencing of partial $5^{\prime}$ non translated genomic region. Ind. $J$. Anim. Sci., 17: 321-322.

39. Aynaud J.M. (1988). Classical Swine Fever and related Viral Infections. Martinus Nijhoff Publishers, Boston, pp. 165-180.

40. Ferrari M. (1992). A tissue culture vaccine with lapinized Chinese (LC) strain of hog cholera virus (HCV). Comp. Immunol. Microbiol. Inf. Dis., 15: 221-228.

41. Vandeputte J., Too H.L., Ng F.K., Chen C., Chai K.K., Liao A. (2001). Adsorption of colostral antibodies against classical swine fever, persistence of maternal antibodies, and effect on response to vaccination in 
baby pigs. Am. J. Vet. Res. 62: 1805-1811.

42. Barman N.N., Gupt R.S., Bora D.P., Kataria R.S., Tiwari A.K., Roychoudhury P. (2010). Molecular Characterization of Classical swine fever virus Involved in the Outbreak in Mizoram. Ind. J. Virol.,21(1):76-81.

43. Desai G.S., Sharma A., Kataria R.S., Barman N.N., Tiwari A.K. (2010). 5'-UTR-based phylogenetic analysis of Classical swine fever virus isolates from India. Acta Virologica, 54(1): 79-82.

44. Sarma D.K., Mishra N., Vilcek S., Rajukumar K., Behera S.P., Nema R.K., Dubey P., Dubey S.C. (2011). Phylogenetic analysis of recent classical swine fever virus (CSFV) isolates from Assam, India. Comp. Immunol. Microbiol. Infect. Disease. 34(1): 11-15.

45. Patil S.S., Hemadri D., Veeresh H., Sreekala K., Gajendragad M.R., Prabhudas K. (2011). Phylogenetic analysis of NS5B gene of classical swine fever virus isolates indicated plausible Chinese origin of Indian subgroup 2.2 viruses. Virus Gene., in press.

46. Chakraborty S., Veeregowda B.M., Chandra Naik B.M., Rathnamma D., Isloor S., Venkatesha M.D., Leena G., Veeresh H., Patil, S.S. (2011). Molecular characterization and genogrouping of classical swine fever virus isolated from field outbreaks. Ind. J. Anim. Sci., 81(8): 21-25.

47. Deng M.C., Huang C.C., Huang T.S., Chang C.Y., Lin Y.J., Chien M.S., Jong M.H. (2005). Phylogenetic analysis of classical swine fever virus isolated from Taiwan. Vet. Microbiol., 106: 187-193.

48. Leifer I., Hoffmann B., Hoper D., Rasmussen T.B., Blome S., Strebelow G., Horeth-Bontgen D., Straubach C., Beer M. (2010). Molecular epidemiology of current classical swine fever virus isolates from wild boar in Germany. J. Gen. Virol., 91: 2687-2697. 